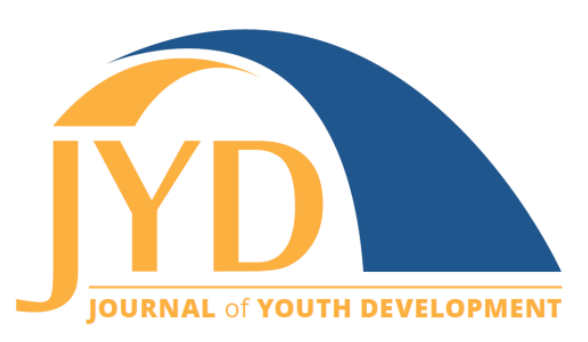

http://jyd.pitt.edu/ | Vol. 16 Issue 2-3 DOI 10.5195/jyd.2021.1041 | ISSN 2325-4017 (online)

\title{
Give Us More Credit! Recommendations for Young and Adult Researchers on Conducting Adolescent-Led Research
}

\author{
Georgiana Vasiloiu \\ Children's Consultative Committee of World Vision Romania
}

Julia Smith-Brake

World Vision International

julia_smith-brake@wvi.org

\section{Simona Eugenia Mihai}

World Vision Romania

simona_mihai@wvi.org

\begin{abstract}
Youth participatory action research, child-led research, and child-led activism are being increasingly employed to counter adultism in social work and development contexts, in a way to break down barriers for young people to have their voices heard on issues and decisions about their lives. This commentary comprises 2 open letters from a young researcher and advocate for children's well-being and rights in Romania. The first letter is addressed to fellow young people and shares the journey of learning about and subsequently researching the issue of sexual violence, as well as a call to young people to stand up and use their voice to bring attention to issues important to them. The fear and anxiety of doing something new, that is usually in an adult space, cedes to empowerment and confidence found through the process. The second letter is addressed to adult researchers and practitioners and shares the methodology and findings of the child-led research project, lessons learned, and recommendations for adults engaging in child-led research. A key recommendation is for adults to support child researchers without manipulating the process, and to give young people more credit in commonly adult-held spaces.
\end{abstract}

Key words: child-led research, adultism, youth advocacy

(cc) EY New articles in this journal are licensed under a Creative Commons Attribution 4.0 License. This journal is published by the University Library System, University of Pittsburgh and is cosponsored by the University of Pittsburgh Press. The Journal of Youth Development is the official peer-reviewed publication of the National Association of Extension 4-H Youth Development Professionals and the National AfterSchool Association. 


\section{Give Us More Credit!}

\section{Background}

The positive youth development (PYD) approach emphasizes adolescents as agents in their own development (Lerner et al., 2005; Lerner \& Barton, 2000) and in decision making about their lives (UNCRC Article 12). Adolescents are in a time and space to both exert control and experience control by those around them, including peers and adults: "agents in their lives who, by virtue of position and power, can either suppress or encourage exploration, selection, and optimization" (Benson et al., 2007, p. 904). Furthermore, sharing power with adolescents, in decision making, for example, can enhance both their development and the efficacy of institutions with which adolescents engage (Zeldin, 2010).

An obstacle to adolescent agency and decision making is adultism, "the power adults have over children" (Flasher, 1978, p. 517), but more recently defined as "prejudice and accompanying systematic discrimination against young people" (Gregoire \& Jungers, 2007, p. 65). Bell (1995) argues, ultimately, adultism is about treating children as inferior to adults and using their age as a justification for disrespecting and mistreating them; acknowledging the needs of children at different life stages, as well as varying cultural and societal norms, Bell proposes patterns of adultism in any context can result in lower self-confidence, feelings of worthlessness or powerlessness, and destructive and self-destructive actions. It can thus be said that adultism is a global social norm, lived out in different ways depending on how cultures, religions, and institutions view and communicate about their children.

Bettencourt (2018) posits that youth participatory action research (YPAR) is one way to challenge adultism and can "serve as a tool for liberation when approached as a contact zone, problem-posing education, and a process rather than a product" (Abstract). A small but growing number of child-focused organisations are now opening their evidence-gathering methodologies to include child-led research (see Cuevas-Parra \& Tisdall, 2019b; Graham et al., 2017; Knotts, 2010; Michail, 2014).

Georgiana Vasiloiu is a 17-year-old leader, advocate, and researcher in Romania. She is a member of the Children's Consultative Committee of World Vision Romania; a child rights advocate who has spoken publicly before the European Union and to the Government of Romania's Minister of Education, as well as to children and peers on issues of sexual violence and pandemic health safety; and a lead researcher on Our Research, Our Rights - Ending violence against children through the lens of child researchers (World Vision, 2020). Our Research, Our Rights was a joint project between World Vision and a group of young 


\section{Give Us More Credit!}

researchers who chose a topic, designed the instrument, collected and analysed data, wrote the final report, and disseminated their findings to child and adult audiences in their home communities and abroad.

This piece comprises two open letters by Georgiana Vasiloiu. The main purpose is to offer recommendations to both adolescent and adult researchers on how to work together and engage in adolescent-led research. As a joint venture between the authors, we hope to demonstrate our belief in challenging adultism and in applying the principles of PYD by making space for Georgiana to share both the results of her YPAR project and by amplifying her voice on a topic that affects her work as a young researcher. Georgiana, her community, country, and region have already benefited by her involvement in YPAR and PYD and amplifying her voice on a larger stage is the logical progression of operationalising these principles.

As the adult co-author, I (Julia Smith-Brake) have supported her in brainstorming the overall vision, asked questions to help her write, probed for detail on ideas, and co-formatted her writing; however, I have not rewritten her words or added my own interpretations of her words. Our third co-author also supported Georgiana in thinking through examples and overall themes; where invited by Georgiana, we have included her input as quoted text. Georgiana chose to write two letters to facilitate access for young readers and to make clear what is aimed directly at adult practitioners, who may practice adultism, even unconsciously: "Maybe adults treat children this way and they don't even realise it" (Georgiana Vasiloiu, personal communication, September 17, 2020). For my own adultism bias, I also apologise.

\section{Open Letter to Young People}

Dear Young People, Dear Friends,

When I think of violence, I believe that we can see it everywhere, more or less. Sexual violence, for instance, is a taboo subject here in Romania. Sadly, until something bad happens, no one pays that much attention to it. Some people choose to ignore it and if we don't do anything about it, it will get even worse, and more children will become victims of it.

A few months after I joined a World Vision project for high school students in rural areas, I found out about the Children Consultative Committee (CCC) from the project coordinators in my county. Even though I didn't know what to expect I decided to be a part of it. The CCC includes 12 children from counties all around Romania who were elected by vote by their colleagues. 


\section{Give Us More Credit!}

Belonging to different communities helps us a lot because we have different stories, experiences, and opinions. We are different individuals, but somehow the same, and from this beautiful mix of personalities we are able to come with unique ideas.

Thanks to World Vision, I developed a lot of skills and it helped me with my social anxiety. That's why I realised that I want to help other children to overcome this. I know that it doesn't go away, it's still there, sometimes it's worse than ever, but sometimes there are days when you don't feel as bad as you used to because of the people who are around and because you are able to see the results of your work. I met a lot of children who were struggling with the same problems as me. It's good to know that I'm not alone.

My colleague in World Vision describes the success of the CCC: "The World Vision Romania (WVR) CCC was a regional project that aimed to empower children and youths to become active citizen [sic] of their own community, identify and address certain needs related to children rights. The successful results of this project and the way children and youths managed to bring their own ideas and recommendations to the attention of national and international authorities, made WVR realise how powerful their voices are, their great potential in advocacy initiatives, and the power of partnership between children and adults. Starting from this point, the 12 members of the Children Consultative Committee were actively involved in discussions with WVR leadership, European institutions, and WVR board members and have played an active role in decision making towards our programs and approaches. They were supported to have their own initiatives, bring their ideas to the table of those who make decisions and permanently capacitated in order to better address their own belief."

I'd like to believe that everywhere there is at least one NGO where you can go and be a volunteer and help your community, but I'm sure that there are still places where it doesn't exist. That shouldn't stop anybody from trying to change something and find people with common interests and create something beautiful. Being a part of an NGO or any volunteering team helps you a lot and also your community.

I remember all of us in the Children's Consultative Committee of World Vision Romania being very disappointed and outraged when we found out how permissive the laws in our country are with the abuser. So, we discussed and, as a group, we decided to conduct research to find out if children are aware of what sexual violence is and if they know all forms of sexual violence. We wanted to share with other children the things we learned that marked us as well. 


\section{Give Us More Credit!}

With the support of WVR we created a questionnaire to collect information about children and young people's level of awareness on child sexual abuse and shared it with our friends in our group chats. The results were alarming, so we conducted information sessions in five counties in Romania (Dolj, Cluj, Valcea, Vaslui, and Ialomita). We answered children's questions about sexual violence, we presented them more information, we wanted it to be an open discussion, to be friendly, and for nobody to feel uncomfortable.

I was excited to get involved in sharing the information to more children because knowledge is power; they are now aware of what to do and whom to address if they experience sexual violence. But also, I was nervous because sexual violence is a taboo subject here in Romania. Honestly, I didn't know all forms of sexual violence; it was an important lesson for me, and also very important for my peers.

Probably most difficult was to decide the ideas we were going to use, then the process and how we had to mobilize fast and find the public to address, depending on age. We had all these different scenarios for each group (children and teens). I was nervous when I had to present all the information to them because I didn't know how they'd react. But it turned out that the information sessions were welcomed by the children, we successfully presented to them all the information and they were very receptive. One participant shared, "I mostly enjoyed the open discussion we had, I felt good to share from my own experience and speak up on my own beliefs."

They were as intrigued as we were when the information was presented to us. Some of them were more talkative and others not as much. We told them that it's a safe place and we're all there to learn from each other and to spread the information. We encouraged them to talk to their friends and inform them, too. I think they wouldn't have been as open if the session had been led by an adult. Another participant shared, "The activity was very good because our older friends explained [to] us what we have to be cautious of, what to do if something bad happens to us."

The project itself was challenging, we learned a lot through it, I learned how to present a project properly, how to speak in front of a crowd and be less anxious. One of the most interesting findings in this research for me, personally, was the amount of misinformation and the fact that the laws are very permissive with the abuser. We were shocked to find out that somehow, it's the victim's fault if he or she was abused. That, of course, it is not true, but sadly, there are many people [here] who think in that way. 


\section{Give Us More Credit!}

It was a great experience because I demonstrated to myself that I can do that, I can help somebody and help myself, too. All this experience as a young researcher demonstrated to me that no matter your age, who you are, or where you're from, if you want to change something and help others you can do it (and of course, if you are supported by the right people). I was shocked, in a good way, to see how many people care about us and are there to listen to us and to help us. They made us feel like we are equals. And, in fact, we really are.

From a child to another child, to be honest with you, I was very scared to participate, talk in front of people, have some sort of responsibility. I was scared that I'd mess up everything, but there were so many people that believed in me and supported me in this whole process. What motivated me the most was that this way I could do something and inform other children. And who knows? Maybe one day that information will help them, or they will help a friend with what they know from us.

My World Vision colleague agrees and adds: "I strongly recommend them to reach out to people that they trust, become members of different school structures, community structures, NGOs, children's clubs or associations and feel confident in expressing what they think is better for their own life."

I do encourage young people to step in the light and change something or at least support those who want to change something. You should be open, creative, and make yourself heard even if maybe there are people who don't want to hear you or are trying to silence you. You should believe in yourself and acknowledge the power you have. We can express ourselves through everything.

\section{Open Letter to Adult Researchers}

Dear Adult Practitioners and Researchers,

World Vision Romania (WVR) is part of the global campaign "It takes a world to end violence against children." I, as a member of Children's Consultative Committee of World Vision Romania (CCC WVR), have been exposed to a lot of information about this subject. But in 2019, in CCC's summer school, our World Vision youth empowerment program coordinator explained to us what sexual violence is, how you recognize it, and whom to address if you're a victim. 


\section{Give Us More Credit!}

When I, together with my other colleagues from the WVR CCC, were introduced to the topic of sexual violence against children, even though we've done a lot of activities related to violence in general, we were shocked. We were shocked to find how many cases of children are reported annually in Romania, about the circumstances this happens in, about the victims and abusers, and most of all, to see that laws are very permissive with the abuser.

After being helped to understand the phenomenon of sexual violence, we decided to get involved in informing even more children about the profile of the abuser, signs of concern, whom to address, and so on. We conducted information sessions for our peers in five areas from Romania, and around 800 children were involved. After that we wanted to see, even more, what children think about sexual violence, so we conducted an online survey, with the support of WVR.

The research took place in December 2019 and January 2020. We wanted it to reach more children so we decided that an online questionnaire would be the best option, also because the winter break was coming, and the weather wasn't favorable for us and for the children to meet. We all did the same thing; it was a group activity, and everybody was a leader in his or her county. We had many calls and discussions with our World Vision group coordinator about the process, how to do it, and if it reached enough children; she constantly gave us suggestions and recommendations.

Our online survey had 14 questions aiming to collect information about children and young people's level of awareness on child sexual abuse and assess their knowledge. The survey was completely confidential, and participants were not asked about their personal experiences with sexual violence. They were told they can leave the online questionnaire any time something made them uncomfortable and could refer to World Vision's national Child Protection Specialist. The easy part about doing research through an online survey was that the information reached the children easily and fast. Most of our time is spent here, online, especially right now due to the coronavirus. The difficult part is that not everybody has access to the Internet and it's important the information reaches them, too. We wish we could reach children in vulnerable categories and low incomes, but in most of the cases they don't have access to the Internet.

The online child-led survey on sexual violence against children was filled in by 1,594 children (68\% girls and $32 \%$ boys), aged between 8 and 18, many of them from high school, in 27 of the 41 counties in Romania. Based on the survey, we realized that there is a lot of misinformation among children. They didn't know all forms of sexual abuse, and if children are 


\section{Give Us More Credit!}

not aware of what violence is, they are vulnerable to it. Four out of five kids do not know that miming the sexual intercourse without actual penetration is a form of sexual abuse; seven out of 10 kids do not know that forcing children to look at images and/or films with explicit sexual content is a form of sexual violence; two out of five kids do not know that touching a child's intimate parts of the body is a form of sexual abuse; seven out of 10 kids do not recognize cases where the abuser removes his/her clothes partially or totally in front of the child as sexual violence; three out of five kids do not know that pressing a child to have sexual intercourse, even if penetration does not happen, is sexual abuse; half of all kids do not know that selftouching intimate parts of the body by the abuser in front of the child is a form of sexual abuse. Even worse, many of them are ashamed and wouldn't talk to their parents or to the authorities about the abuse they've just experienced: Only three out of five kids would talk to their parents, only half would call the police, only one out of five kids would call Child Welfare Services.

The project itself was challenging, we learned a lot through it, I learned how to present a project properly, how to speak in front of a crowd and be less anxious. We were constantly exposed to information about different approaches, we had numerous training processes, so we were quite prepared to approach the research and it was kind of easy to think about it and what we had to do next.

The adult practitioners helped us to understand the phenomenon and prepare to share the information with other children. They helped us with ideas and to finalize the questionnaire so that it would be as complete as possible. They let us lead the presentations and most of the activities. I didn't feel that they had too much control, they were very supportive and made sure that our voices were heard. They listened to us, to our ideas, and helped us to realise them. The adults saw how affected we were after we found out how serious the situation of sexual abuse was here in Romania. We thought of the hundreds of children whose cases have not been done justice to this day. One of those children could have been one of us. So, the subject caught our attention very quickly. It was something for children made by children, and I think they understood that and decided just to be there for us. They saw us as their equals, they treated us as their equals, and believed in our strength. By believing in us they offered the space we needed. We learned from each other.

For instance, instead of telling us exactly what to do, we were asked questions that helped us better understand the whole process, and our answers actually helped us reach the point in 


\section{Give Us More Credit!}

which we decided the strategy, drafted the questions for the questionnaire, and decided whom to address them to.

Thinking of the whole process, of what went well or badly, of how we as children felt doing this, I would suggest that adult practitioners, first of all, should give us more credit and create opportunities to facilitate research-related learning. We, as children, want to have the chance to participate in every step of creating research, starting with the idea until the final result. I think that what they could do is to involve young people more in research, especially when the research is about children because I think that a child can talk and feel more comfortable around another child when it comes to this kind of topic. My adult colleague agrees: "I would like to highlight the importance of diversity in reaching different perspectives and experiences and the power of partnership between adults, children, and youths in reaching common issues and solving problems that affect all of us."

Second of all, we need constant feedback because we need to know that what we're doing is good, we need guidance, but we also want to express ourselves freely so even if they're helping us, they shouldn't manipulate the process. My World Vision colleague shares her perspective as a child participation expert: "There is a very thin line between supporting child-led initiatives and controlling/manipulating them. In order to facilitate correctly and give a proper space for children to discuss, decide on, and implement their own project, you must be patient, never rushing the process and always giving children credit for what they do. If they feel empowered, trusted and have the lead on what they do, the facilitation process becomes very easy. If adults truly trust children and are ready to give them the floor, still being there as supporters, children will do their best to achieve their plans. It is about loving, trusting, and constantly being there for the children! As for the methodologies in working with children, WVI developed several toolkits on how to prepare adults for working alongside children (Cuevas-Parra, 2016; CuevasParra \& Tisdall, 2019a). I strongly believe that the skills can all come naturally if you really believe in the potential of the new generations of children and adolescents."

Third, I would recommend they invest in capacity processes for young people and children, to explain to them, step-by-step, what research requires, what is its goal, what are the topics of interest for children, what they want to focus on, what they do with the information they receive, and how to turn it into a report. Adult practitioners should invest in the formation of children's advisory structures at regional and international levels and allocate funds for trainings on soft skills, media communication, digital, advocacy, etc. I believe that all children are smart and have potential, but there is a big difference between having good ideas and being able to 


\section{Give Us More Credit!}

express them in public. For instance, how to draft a coherent speech in order to keep the attention of the audience; knowing what advocacy is and what the instruments are that you, as a child, can use in order to advocate for what you stand for. When it comes to media and digital, you really have to be taught some tricks that help you learn and have a great result faster.

In conclusion, equality is the best option because we can learn so many things from each other. I'm 17 and I'm not ashamed to say that I can learn something from a 9-year-old and also learn something from a 35-year-old. So why would some adults be ashamed in accepting that they can learn something from a teenager? Yes, I think that there's no reason in being ashamed, we're all different and we all live different lives and experiences; we face different problems. Let's stop judging other people by age. We're all humans, we have feelings and even if we live different lives, we share the same planet. This world would be a way better place if we respected each other more. It doesn't matter what sexuality, colour of skin, or religion you have. First of all, you're human and you deserve to be loved and respected.

Adult researchers must know, recognize, and assume that children's voices need to be heard and highlighted in every context, but especially when there are decisions being made about children. We want to be invited to events within certain consultative structures at national, regional, and international levels. We should be consulted on everything that interests us. When adults don't assume that they know what we're thinking or how we want to be helped, they just let us speak, and that's all we want and need.

\section{Author Note}

Correspondence regarding this article should be directed to Julia Smith-Brake, World Vision International, julia smith-brake@wvi.org.

\section{References}

Bell, J. (1995). Understanding adultism: A major obstacle to developing positive youth-adult relationships. YouthBuild USA. https://actioncivics.scoe.net/pdf/Understanding Adultism.pdf

Benson, P. L., Scales, P. C., Hamilton, S. F., \& Sesma, A., Jr. (2006). Positive youth development: Theory, research, and applications. In R. M. Lerner \& W. Damon (Eds.), Handbook of child psychology: Theoretical models of human development (p. 894-941). John Wiley \& Sons. 
Journal of Youth Development | http://jyd.pitt.edu/ | Vol. 16 Issue 2-3 DOI 10.5195/jyd.2021.1041

Give Us More Credit!

Bettencourt, G. M. (2018). Embracing problems, processes, and contact zones: Using youth participatory action research to challenge adultism. Action Research, 18(2), 153-170. https://doi.org/10.1177/1476750318789475

Cuevas-Parra, P. (2016). Children and young people-led research methodology: An easy guide for young researchers. World Vision International. https://www.wvi.org/sites/default/files/WV-CAY-LedResearch\%20Methodology-03-11-2016\%20FINAL.pdf

Cuevas-Parra, P., \& Tisdall, E. K. M. (2019a). Child-led research: From participating in research to leading it. Addressing inequalities in decision-making. World Vision International and University of Edinburgh. https://www.wvi.org/sites/default/files/2019-06/Research\%20report\%20-Childled\%20research\%20\%20From\%20participating\%20in\%20research\%20to\%20leading\%20it\%20June\%202019\%20\% 28a\%29.pdf

Cuevas-Parra, P., \& Tisdall, E. K. M. (2019b). Child-led research: Questioning knowledge. Social Sciences, 8(2), 44. https://doi.org/10.3390/socsci8020044

Flasher J. (1978). Adultism. Adolescence, 13(51), 517-523.

Graham, A., Simmons, C., \& Truscott, J. (2017). 'I'm more confident now, I was really quiet': Exploring the potential benefits of child-led research. International Journal of Qualitative Studies in Education, 30(2), 190-205. https://doi.org/10.1080/09518398.2016.1242803

Gregoire, J., \& Jungers, C. M. (2007). The counselor's companion: What every beginning counselor needs to know. Lawrence Erlbaum Associates.

Knotts, R. (2010). Child carers: Child-led research with children who are carers. Four case studies; Angola, Nigeria, Uganda and Zimbabwe. Save the Children UK. https://resourcecentre.savethechildren.net/node/3738/pdf/3738.pdf

Lerner, R. M., \& Barton, C. E. (2000). Adolescents as agents in the promotion of their positive development: The role of youth actions in effective programs. In W. J. Perrig \& A. Grob (Eds.), Control of human behavior, mental processes, and consciousness: Essays in honor of the $60^{\text {th }}$ birthday of August Flammer (pp. 457-475). Lawrence Erlbaum Associates.

Lerner, R. M., Theokas, C., \& Jelicic, H. (2005). Youth as active agents in their own positive development: A developmental systems perspective. In W. Greve, K. Rothermund, \& D. Wentura (Eds.), The adaptive self: Personal continuity and intentional self-development (pp. 31-47). Hogrefe \& Huber Publishers.

Michail, S. (2014). Re-crafting child-led research for Australian welfare services: The 'how' of working alongside children. In J. Westwood, C. Larkins, D. Moxon, Y. Perry, \& N. Thomas (Eds.), Participation, citizenship and intergenerational relations in children and young people's lives: Children and adults in conversation (pp. 128-138). Palgrave Pivot. https://doi.org/10.1057/9781137379702 13 
Journal of Youth Development | http://jyd.pitt.edu/ | Vol. 16 Issue 2-3 DOI 10.5195/jyd.2021.1041

\section{Give Us More Credit!}

World Vision International (2020). Our research, our rights: Ending violence against children through the lens of child researchers from Bosnia and Herzegovina, Brazil, Indonesia, Nicaragua, Romania and Sierra Leone. https://www.wvi.org/sites/default/files/202006/DEAR\%20WVI\%20Child\%20led\%20report\%20FINAL.pdf

Zeldin, S. (2004). Youth as agents of adult and community development: Mapping the processes and outcomes of youth engaged in organizational governance. Applied Developmental Science, 8(2), 75-90. https://doi.org/10.1207/s1532480xads0802 2 